\title{
DETERMINAÇÃO EXPERIMENTAL DA CURVA DE POLARIZAÇÃO DE UMA CÉLULA A COMBUSTÍVEL TIPO PEM
}

\author{
T. SANTOS ${ }^{1}$; H. S. MOTA ${ }^{2}$; M. LINARDI ${ }^{3} ;$ R. M. SENNA $^{1}$ \\ ${ }^{1}$ Universidade Federal de São Paulo, Departamento de Engenharia Química. \\ ${ }^{2}$ Faculdade de Economia, Administração e Contabilidade - Universidade de São Paulo. \\ ${ }^{3}$ Instituto de Pesquisas Energéticas e Nucleares -IPEN - Universidade de São Paulo \\ E-mail para contato: rmdesenna@gmail.com
}

RESUMO - A geração de energia elétrica se apresenta como um grande desafio para a humanidade, devido ao seu enorme potencial poluidor, notadamente quando advinda de combustíveis fósseis. No mundo, em 2013, como mostrado no BEN 2016, apenas 13,5\% da matriz energética compunha-se de combustíveis renováveis, sendo no Brasil 41,2\%. Baseado nessas estatísticas pode-se afirmar que a produção de energia no Brasil ainda é predominante de combustíveis fósseis. Uma das alternativas que merece destaque especial é a tecnologia de células a combustível (CAC), pois são dispositivos sustentáveis e não poluentes que oxidam eletroquimicamente o combustível, em geral hidrogênio, gerando energia elétrica e calor. Pretende-se com esse trabalho, mostrar os procedimentos para ensaiar uma CAC unitária, de eletrólito sólido ETEK_HP, composto por uma membrana de náfion (PTFE), de espessura de $115 \mu \mathrm{m}$, sendo o eletrodo constituído por catalisador de platina, com carga de $0,4 \mathrm{mg} / \mathrm{cm}^{2}$ no ânodo, e $0,6 \mathrm{mg} / \mathrm{cm}^{2}$ no cátodo, suportados em carbono. O ponto ótimo de operação da CAC pela eficiência do MEA foi em $433 \mathrm{mV} @ 1120 \mathrm{~mA}$, de característica linear, e não está sujeito, significativamente, aos fenômenos de ativação e transferência de massa. Notase que entre $365 \mathrm{mV}$ e $558 \mathrm{mV}$, a densidade foi acima de 0,45 W/ $\mathrm{cm}^{2}$, e consequentemente a potência da CAC acima de $11 \mathrm{~W}$. O consumo de oxigênio e hidrogênio foi mais eficiente acima de $800 \mathrm{mV}$. 


\section{INTRODUÇÃO}

Apesar de enorme relevância social e econômica, as atividades relacionadas à coleta, distribuição e uso de energia causam enormes impactos ao meio ambiente, liberando substâncias para a atmosfera, fontes de água e solo, comprometendo a saúde e a sobrevivência de todo o ecossistema terrestre. As várias etapas dos sistemas energéticos, como as atividades extrativistas, sua conversão, distribuição e uso, estão estreitamente relacionados entre si, e com o desenvolvimento de toda a humanidade. Há uma necessidade crescente de encontrar soluções para os efeitos negativos da cadeia de produção, distribuição e processos de uso de energia, a fim de minimizar as perdas sociais, ambientais e econômicas. O crescimento populacional, em especial nos países em desenvolvimento, e o crescente consumo de recursos energéticos, por habitante, vêm trazendo preocupações relativas à sustentabilidade das atividades humanas (ALDABÓ, 2004; BONIFÁCIO, 2011; FUKUROZAKI, 2006).

As células a combustível sugiram em 1839, devido aos trabalhos de pesquisa eletroquímica desenvolvidos por William Grove. No entanto, a primeira célula a combustível com aplicação prática, desenvolvida por Francis Bacon, ocorreu na Inglaterra em 1932. O módulo de Célula a combustível objeto dessas pesquisas foi uma unidade de $7 \mathrm{~W}_{\mathrm{e}}$ (quilowatt elétrico), alimentado pelos gases de hidrogênio e oxigênio, suportados em um eletrólito alcalino (COOK, B., 2002).

Objetiva-se mostrar, além dos resultados, os procedimentos para o ensaio de uma unidade de célula a combustível, constituída de um eletrólito sólido de $25 \mathrm{~cm}^{2}$ de área útil superficial, e potência e tensão nominal de operação de 7W@700mV. As etapas do ensaio são mostradas na forma de uma abordagem sistêmica envolvendo diversos aspectos tecnológicos, de modo contribuir para uma maior divulgação dos procedimentos e métodos de verificação da qualidade dessa tecnologia.

\section{Princípio Básico de Funcionamento das Células PEMFC}

A célula a combustível é, em síntese, um transformador de energia eletroquímica, oxida hidrogênio no ânodo, pólo negativo, e reduz oxigênio no cátodo, pólo positivo, por meio de eletrodos de difusão gasosa, como mostrado na figura (1).

Numa célula a combustível tipo (PEM), duas reações de meia célula ocorrem, simultaneamente, sendo uma reação de oxidação, perda de elétrons, no ânodo e, uma reação de redução com ganho de elétrons, no cátodo. Essas duas reações perfazem as reações de oxidação-redução na célula a combustível, responsáveis pela formação da água a partir dos elementos gasosos hidrogênio, oxigênio e calor, também a liberação da energia elétrica em forma de fluxo de elétrons, pelo circuito elétrico externo à membrana polimérica trocadora de íons. As equações químicas que ocorrem em uma célula tipo PEM são mostradas em (1), (2), (3):

$$
\text { Reação anódica: } \quad \mathrm{H}_{2} \rightarrow 2 \mathrm{H}+2 \mathrm{e}-
$$


$\begin{array}{lll}\text { Reação catódica: } & 1 / 2 \mathrm{O}_{2}+2 \mathrm{e}-+2 \mathrm{H}+ & \rightarrow \mathrm{H}_{2} \mathrm{O} \\ \text { Reação geral: } & \mathrm{H}_{2}+1 / 2 \mathrm{O}_{2} & \rightarrow \mathrm{H}_{2} \mathrm{O}\end{array}$

Figura 1: Diagrama simplificado de uma Célula a Combustível Unitária PEM

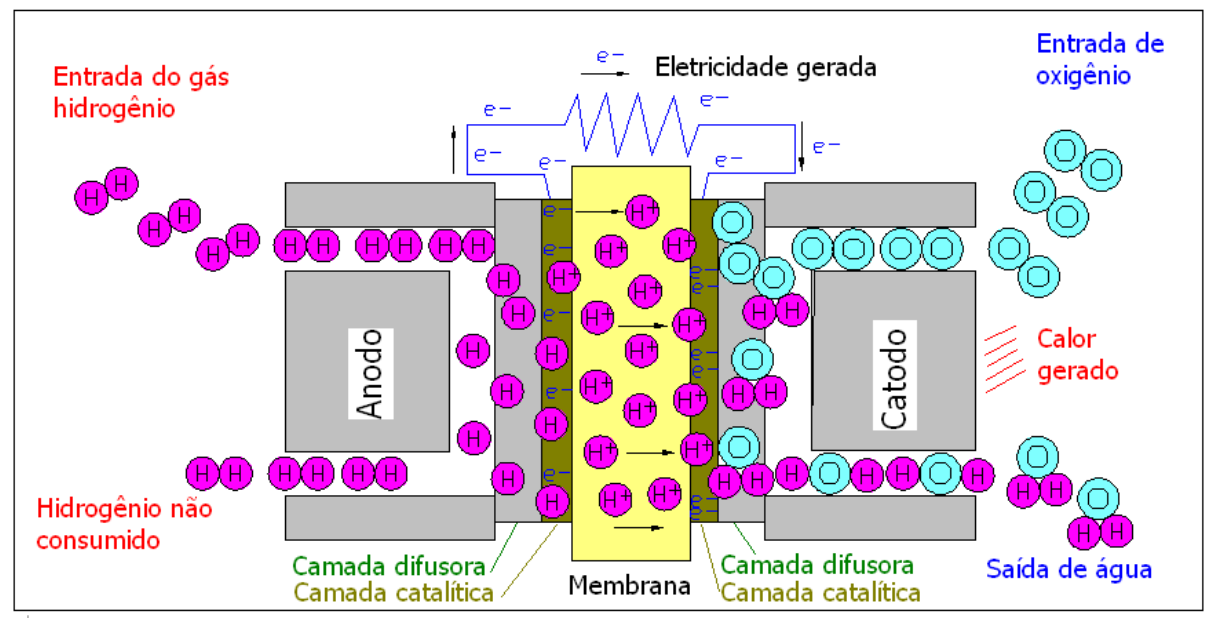

Fonte: Autor, adaptado de: Linardi, (2010), Capítulo 4.

No ânodo, as moléculas de hidrogênio entram em contato com o catalisador de platina na superfície do eletrodo de difusão gasosa. As moléculas de hidrogênio se quebram aderindo à superfície da platina de forma separada através de ligações fracas, ligações polares, de H-Pt. Ocorrendo a quebra da molécula de hidrogênio a reação ocorre. Cada átomo de hidrogênio lança os seus elétrons através de um circuito, carga, externo à membrana polimérica, que é um isolante elétrico, indo ao encontro do íon oxigênio no cátodo. Por seu lado o íon hidrogênio atravessa a membrana trocadora de prótons associado à água, na forma de $\mathrm{H} 3 \mathrm{O}+$, indo de encontro ao cátodo, deixando o catalisador de platina livre para promover a quebra de novas moléculas de hidrogênio (CUNHA, E. F.; 2009).

No cátodo as moléculas de oxigênio entram em contato com um catalisador de platina na superfície do eletrodo de difusão gasosa. As moléculas de oxigênio aderemse, separadamente, à superfície do eletrodo de platina, formando ligações fracas O-Pt, ligações polares, isto cria as condições necessárias para que a reação de redução ocorra. Cada átomo de oxigênio, então, deixa o catalisador de platina, combinando com dois elétrons e dois íons de hidrogênio para formar uma molécula de água. As reações de redução agora se completam. O catalisador de platina no eletrodo de difusão gasosa cátodo está agora livre para enfraquecer as ligações de novas moléculas de oxigênio (LINARDI, 2010). 


\subsection{Eletrodo de Difusão Gasosa}

Como mostrado na figura (1), o eletrodos de difusão gasosa são os elementos que associados a cada face da (PTFE) dão a configuração física ao (MEA). Possuem estrutura dividida em camada catalítica e camada difusora, sendo que a camada catalítica objetiva tornar mais eficiente à atividade dos eletrocatalisadores de platina, que são associados a outros elementos químicos, tais como os metais e óxidos, na forma de ligas, com o objetivo de acelerar as reações, bem como reduzir custos de produção. Por se encontrarem impregnados nas partículas de carbono ativo e, carbono ativo grafitado da sua estrutura porosa possibilita um contato íntimo do gás, do líquido e, da PTFE. A camada difusora é formada por um fino tecido de carbono, termicamente prensada, sobre a camada catalítica (COOK, B., 2002).

\subsection{Energia de Formação da Água}

Essa reação exotérmica de formação da água a partir dos gases oxigênio e hidrogênio tem uma entalpia, da ordem, de $-285,8 \mathrm{~kJ}$ de energia por mol de água formada. A energia disponível para trabalho se reduz em função da temperatura. Por exemplo: em $25^{\circ} \mathrm{C}$, a uma atmosfera de pressão, a energia livre disponível para o trabalho é por volta de $-237,1 \mathrm{~kJ} / \mathrm{mol}$. Esta energia se apresenta na forma de fluxo de elétrons (corrente elétrica) e de calor (FELTRE, R., 2004).

\subsection{Membrana Eletrolítica Polimérica Trocadora de Prótons}

O material da membrana usado em uma célula tipo PEM é um polímero produzido em formato laminar com espessuras, que variam normalmente, de 50 a $175 \mu \mathrm{m}$ (micrometros). A camada catalítica do eletrodo é aplicada em ambos os lados da membrana (PTFE) e a seguir cortada nas dimensões desejadas (CUNHA, E. F.; 2009).

Dos materiais usados o mais comum é o Nafion ${ }^{\circledR}$, desenvolvido na década de 1970, pela Dupont, o Nafion ${ }^{\circledR}$ consiste de uma cadeia de politetrafluoretileno (PTFE), comumente conhecido como Teflon, que forma a estrutura base da membrana tipo PEM. Ligados ao final da cadeia estão os grupos de ácidos sulfônicos $\left(\mathrm{HSO}_{3}\right)$, sendo que o lado da cadeia química em que se encontra o grupo sulfônico apresenta característica higroscópica e é responsável pela condução dos íons e da água pelo interior da membrana, sendo que o outro lado possui comportamento oposto em relação à água (LINARDI, 2010).

Para a membrana conduzir íons de forma eficiente a estrutura do lado do grupo sulfônico deve absorver quantidades razoáveis de água. Com essa região adequadamente hidratada, o íon hidrogênio está habilitado a mover-se livremente pelo interior da membrana, cumprindo o papel que dele é esperado. Essa membrana é resistente quimicamente e, obteve, e ainda obtém grande sucesso devido à sua relativa longevidade, comparativamente a outras membranas, que ocorreram anteriormente à sua descoberta. $\mathrm{O}$ advento da membrana de Nafion ${ }^{\circledR}$ surgiu em decorrência de trabalhos de eletrólise de cloro com soda cáustica (LINARDI, 2010). 


\subsection{Comportamento Elétrico e Eficiência}

Ao fazer a transformação da energia química em energia elétrica, uma célula a combustível com comportamento ideal deveria entregar o potencial de $1,23 \mathrm{~V}$, mas, de fato, entrega aproximadamente $1,0 \mathrm{~V}$ quando submetida à pressão de uma atmosfera, temperatura de $25^{\circ} \mathrm{C}$. O valor de $1,23 \mathrm{~V}$ não é atingido. Uma das causas é devido ao calor desprendido durante as reações, bem como por sua temperatura de operação por volta dos $80^{\circ} \mathrm{C}$. Também contribui para essa queda de potencial outros fatores listados, em (2.4.1), (2.4.2) que se denominou de perdas primárias (WENDT, H.; LINARDI, M.; ARICÓ, E. 2002).

\subsubsection{Perdas por Ativação}

Perdas por ativação são as devidas às condições iniciais da reação e são influenciadas de forma significativa pela ação do catalisador. Quanto mais eficiente o catalisador menor a energia necessária para processar a reação, e neste papel a platina oferece excelentes resultados, entretanto é elevado o custo incorrido em sua aplicação exclusiva. Atualmente, novas técnicas de se encontram disponíveis, onde a platina é associada a metais e óxidos, o que propiciou significativas reduções de custos e aumento de eficiência (SPINACÉ, E.V., OLIVEIRA NETO, A.; LINARDI, 2004).

Essas questões têm fomentado inúmeras pesquisas de materiais melhores adaptados ao processo catalítico, e que possuam preços competitivos. Um fator importante na limitação na densidade de potência entregue pela ação da célula é a velocidade em que as reações ocorrem no seu interior. A reação no cátodo (redução do oxigênio) é por volta de 100 vezes menor que a reação no Ânodo (Brian Cook, 2002). Dessa constatação pode-se concluir que o gargalo tecnológico está localizado e, é aí que se deve dedicar atenção.

O arraste de combustível pelo interior do eletrólito, e a corrente elétrica interna também são fatores importantes para a elevação da queda no potencial elétrico e perdas de rendimento. Esses fatores ocorrem mesmo ao se considerar a elevada resistência eletrônica do eletrólito. (WENDT, H.; LINARDI, M.; ARICÓ, E. 2002).

\subsubsection{Perdas por concentração ou transporte de massas}

São as resultantes da redução da concentração de gás hidrogênio e oxigênio nos elétrodos. Isto pode ser observado na situação que segue: a lógica de funcionamento é que após a reação novos gases devem chegar até os eletrodos e, conseqüentemente à camada catalisadora, para tornar o processo contínuo. No cátodo, com o iniciar do processo, começa a formação de água, que se acelera para altas densidades de corrente, provocando restrições ao acesso do oxigênio, o que reduz o rendimento. Uma ação do sistema de controle da célula a combustível deve atuar imediatamente, mantendo o suprimento de oxigênio (LINARDI, 2010). 


\section{METODOLOGIA}

\subsection{O Laboratório de Células a Combustível do IPEN/USP}

Os gases oxigênio, hidrogênio e nitrogênio de purga para atender ao laboratório é feito por meio de tubulações. Logo na saída dos reservatórios existem medidores de vazão e de pressão de gás. Ao serem acessados no laboratório, os gases, são novamente medidos nos medidores de fluxo de massa, de comando manual, para atender aos experimentos. Logo na saída do medidor de fluxo de massa os gases passam por um processo de umidificação, aquecimento e elevação da pressão de vapor. No umidificador (ânodo) a temperatura deve ser mantida, manualmente, em $85^{\circ} \mathrm{C}$ e, na célula a $70^{\circ} \mathrm{C}$. A célula a combustível deve ficar trabalhando por um período de uma a duas horas, com o intuito de estabilizar as condições de funcionamento para obter um ensaio com melhor precisão e assim evitar oscilações grosseiras nos resultados do ensaio (CUNHA, E. F. 2009).

\subsection{Descrição do Experimento no IPEN/USP}

Inicia-se o experimento após o laboratório já estar pronto para o ensaio, confere-se o ajuste que será dado à carga dinâmica, configura-se o regulador para o início da escala, que deve atingir ao final valor próximo a 38A. Considera-se que procedimentos preliminares já foram anteriormente executados como as rotinas de purga de nitrogênio no ânodo, bem como a ligação da célula a combustível ser ensaiada por um intervalo de uma a duas horas, para a estabilização da temperatura de ensaio (LINARDI, M.; 2010).

Ajusta-se a carga dinâmica para solicitar da célula 38 A, inicialmente na faixa superior de capacidade da carga e, progressivamente, a cada dois ampere de redução na corrente, com espera de dois minutos, a uma temperatura de célula mantida em $70^{\circ} \mathrm{C}$, pressão atmosférica e, fluxo de gás conforme tabela das vazões dos reagentes, em função da corrente, acrescido de excesso estequiométrico em $50 \%$.

Conclui-se o experimento no momento em que o ajuste da carga dinâmica atingir corrente elétrica zero. Para a faixa de valores de corrente entre dois e zero, visando melhor definição da região de ativação da célula, as medições devem ser feitas de duzentos em duzentos miliampere.

A carga dinâmica possui três faixas de ajuste, a membrana de náfion possui uma espessura de $115 \mu \mathrm{m}$, o catalisador de platina é do tipo ETEK_HP, possui carga de platina de $0,4 \mathrm{mg} / \mathrm{cm}^{2}$ no ânodo e, $0,6 \mathrm{mg} / \mathrm{cm}^{2}$ no cátodo. No canal três do medidor de fluxo de massa supre-se o hidrogênio e, no canal quatro o oxigênio (CUNHA, E. F.; 2009).

De modo complementar ao que foi descrito até o momento, faz-se a aquisição de dados suportado em uma placa eletrônica dedicada ou procede-se de forma manual com o preenchimento de formulário, onde se devem anotar os valores de tensão em $\mathrm{mV}$, entregues pela célula à carga dinâmica, e a correspondente corrente elétrica após cada ajuste de corrente fornecida, no dial da carga dinâmica (LINARDI, M.; 2010). 


\section{Congresso Brasileiro de Engenharia \\ Química em Iniciação Científica \\ UFSCar - São Carlos - SP \\ 16 a 19 de Julho de 2017}

CONGRESSO BRASILEIRO DE ENGENHARIA

\section{RESULTADOS E DISCUSSÃO}

Os valores medidos são conferidos e processados. Mostra-se o resultado do experimento na figura (2) e (3) denominadas respectivamente de Curva de Polarização e Curva de Potência Máxima da Célula a Combustível. Importantes informações são obtidas dessas duas Curvas, resultante dos ensaios:

Figura 2: Ensaio de Polarização de uma Célula a Combustível Unitária PEM

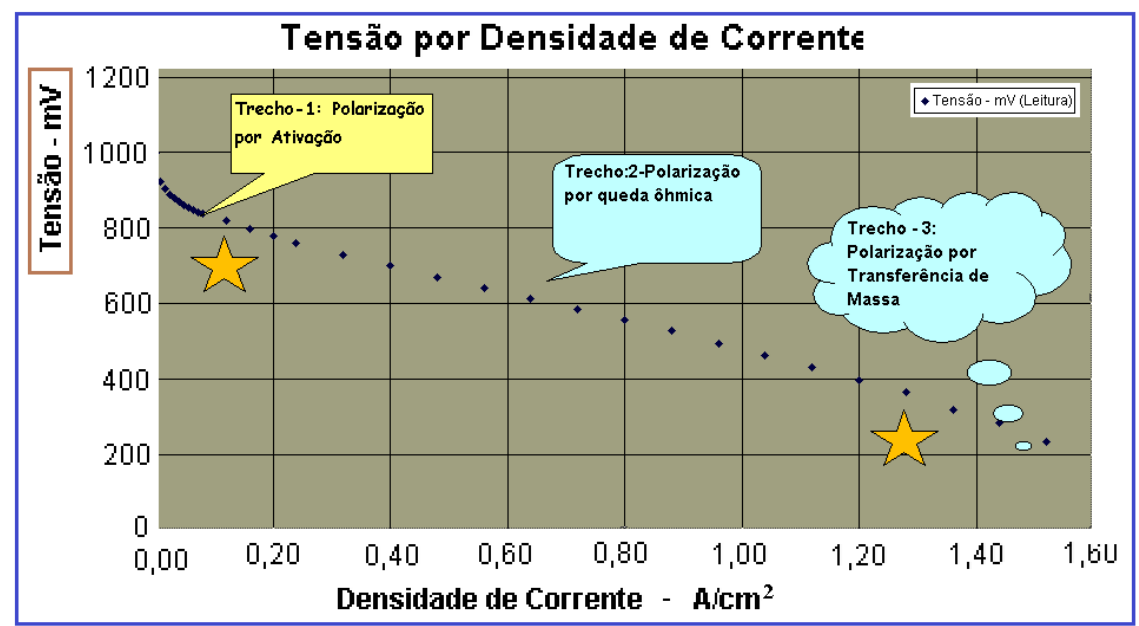

Fonte: Autor, ensaiado no laboratório do IPEN/USP.

Figura 3: Densidade de Potência Máxima: Célula a Combustível Unitária PEM

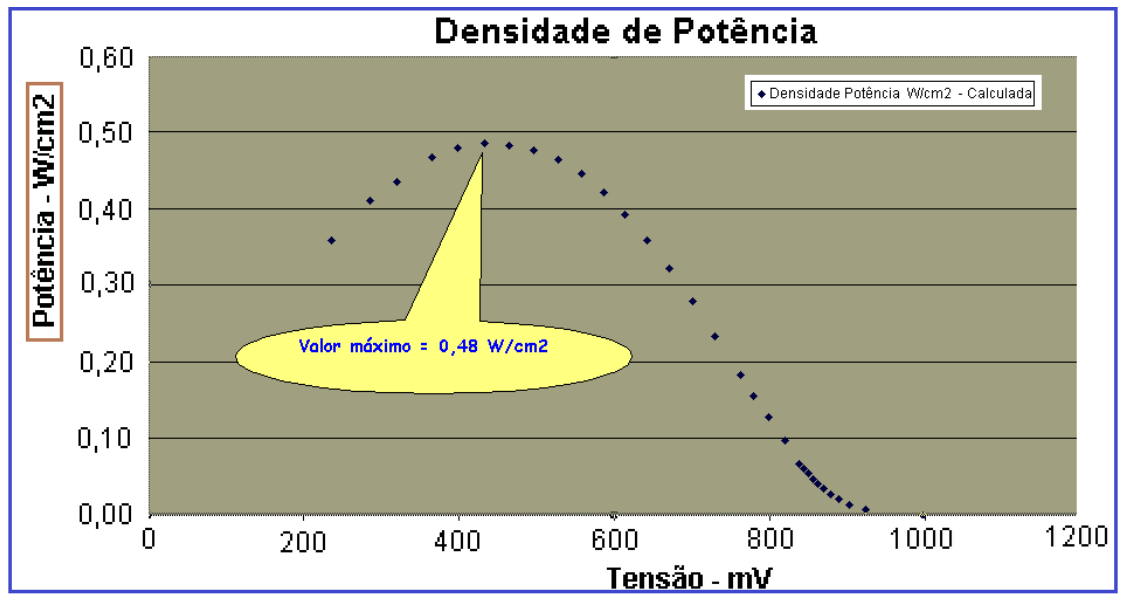

Fonte: Autor, ensaiado no laboratório do IPEN/USP.

I - Trecho dominante típico de polarização por ativação, em (2): localiza-se próximo ao potencial de $838 \mathrm{mV}$, e a corrente demandada na faixa de zero a $80 \mathrm{~mA} / \mathrm{cm}^{2}$; 
II - Trecho dominante típico de polarização por queda ôhmica, em (2): localiza-se na faixa de $838 \mathrm{mV}$ a $365 \mathrm{mV}$, e corrente demandada na faixa de $80 \mathrm{~mA} / \mathrm{cm}^{2}$ $1280 \mathrm{~mA} / \mathrm{cm}^{2}$;

III - Trecho dominante típico de polarização por transferência de massa, em (3): localiza-se na faixa de $365 \mathrm{mV}$ a $200 \mathrm{mV}$, e corrente demandada na faixa de $1280 \mathrm{~mA} / \mathrm{cm}^{2}$ a $1500 \mathrm{~mA} / \mathrm{cm}^{2}$;

IV - A densidade de potência máxima, em (3): 0,48 W/cm².

\section{CONCLUSÕES}

Conclui-se, ao avaliar os resultados desse ensaio, que o ponto ótimo de operação da célula a combustível na visão da eficiência do uso do MEA se localiza em $433 \mathrm{mV}$, densidade de corrente $1120 \mathrm{~mA}$. Esse ponto se localiza na região governada pelo efeito predominante de perdas ôhmicas, que é linear e, não está sujeito, significativamente, aos fenômenos de ativação e transferência de massa. Para se definir um ponto de operação outras considerações podem ser feitas, como: a vida útil da membrana, uma satisfatória relação entre custo de aquisição e a quantidade de energia fornecida, entre outras possibilidades. Outros ensaios podem ser necessários para uma melhor decisão, tais como: durabilidade, confiabilidade, estudo de viabilidade econômica, características de funcionamento para situações de flutuação de carga, entre outros.

Nota-se que na faixa de tensão entre $365 \mathrm{mV}$ e $558 \mathrm{mV}$, a densidade de potência se encontra num patamar elevado, e acima de $0,45 \mathrm{~W} / \mathrm{cm}^{2}$, e consequentemente a potência total entregue pela célula se encontra acima de $11 \mathrm{~W}$, configura uma região de interesse no que tange ao melhor rendimento do MEA por área. Quando se analisa o ponto de operação do ponto de vista do consumo de oxigênio e hidrogênio o melhor ponto de operação se localiza acima de $800 \mathrm{mV}$.

\section{REFERÊNCIAS}

ALDABÓ, R. Célula Combustível a Hidrogênio - Fonte de Energia da Nova Era. São Paulo: Artiber, 2004. 182p

BEN - BALANÇO ENERGÉTICO NACIONAL 2016. Rio de Janeiro. Brasil.

COOK, BRIAN. Introduction to fuel Cells and hydrogen technology. Engineering Science and Education Journal, published by Elsevier. V. 11, issue 6. Dec. 2002. P. 205-216.

CUNHA, E. F. Avaliação e Aplicação de Tecnologias de Células a Combustível tipo PEMFC Desenvolvidas no IPEN em um Módulo de 500W de Potência Nominal. 2009. 135p. Tese (Doutorado em Ciências - Tecnologia Nuclear), Instituto de Pesquisas Energéticas e Nucleares, IPEN/USP, São Paulo, Brasil.

FELTRE, R. Físico Química. Editora Moderna. 6. Ed. 2004, 417p. São Paulo, Brasil. 


\section{Congresso Brasileiro de Engenharia \\ Química em Iniciação Científica \\ UFSCar - São Carlos - SP

LINARDI, M.; Introdução à Ciência e Tecnologia de Células a Combustível. São Paulo, SP, Brasil: Altiber Editora, primeira edição, 2010. 152p. ISBN: 978-85-88098-52-7

SPINACÉ, E.V., OLIVEIRA NETO, A.; LINARDI, M. Electro-oxidation of methanol and ethanol using PtRu/C electro catalysts prepared by spontaneous deposition of platinum on carbon-supported ruthenium nanoparticles. Journal of Power Sources, v. 129, issue 2, p. 121-126, 22 Apr. 2004

WENDT, H.; LINARDI, M.; ARICÓ, E. Células A Combustível de Baixa Potência Para Aplicações Estacionárias, Química. Nova, São Paulo, SP. Vol. 25, No. 3, p. 470-476, 2002. 